\title{
PENGARUH BUDAYA ORGANISASI DAN MOTIVASI KERJA TERHADAP KINERJA ARYAWAN PADA PT BANDAR ABADI SHIPYARD
}

\author{
Lia Anggelina ${ }^{1}$ ) Inggrid Wahyuni Sinaga ${ }^{2}$ ) \\ 1) Prodi Administrasi Bisnis Terapan Politeknik Negeri Batam, email: liaanggelina93@yahoo.com \\ 2) Prodi Administrasi Bisnis Terapan Politeknik Negeri Batam, email: Inggrid@ polibatam.ac.id
}

\begin{abstract}
PT. Bandar Abadi Shipyard is a company engaged in manufacturing and the company is working to improve the quality and quantity of production in the ship building and ship repair. The purpose of this study was to determine the influence of organizational culture variables and work motivation on employee performance at PT. Bandar Abadi Shipyard. The study population was 50 people and the samples used are saturated sampling technique. This study using multiple linear regression data analysis with the help of computer software SPSS version 20.00. Analysis of the data used to test the validity and reliability levels, classical assumptions and hypothesis testing. Results from this study indicate that the organizational culture $\left(X_{1}\right)$, and work motivation $\left(X_{2}\right)$ positive and significant impact on employee performance $(Y)$ and simultaneously the organizational culture $\left(X_{1}\right)$ and work motivation $\left(X_{2}\right)$ positive and significant impact on employee performance $(Y)$
\end{abstract}

Keywords : Organizational Culture, Work Motivation, Employee Performance

\begin{abstract}
Abstrak
PT. Bandar Abadi Shipyard merupakan perusahaan yang bergerak di bidang manufaktur dan perusahaan ini bekerja dalam meningkatkan kualitas dan kuantitas produksi pada pembangunan kapal dan perbaikan kapal. Tujuan dari penelitian ini adalah untuk mengetahui pengaruh variabel budaya organisasi dan motivasi kerja terhadap kinerja karyawan pada PT. Bandar Abadi Shipyard. Populasi penelitian ini adalah 50 orang dan sampel yang digunakan yaitu teknik sampling jenuh. Penelitian ini menggunakan alat analisis data regresi linier berganda dengan bantuan software komputer untuk statistik SPSS versi 20.00. Analisis data digunakan untuk menguji tingkat validitas dan reliabilitas, asumsi klasik, dan pengujian hipotesis. Hasil dari penelitian ini menunjukkan bahwa Budaya Organisasi (X1), dan Motivasi Kerja (X2) berpengaruh positif dan signifikan terhadap kinerja karyawan (Y) dan secara simultan budaya organisasi (X1) dan motivasi kerja (X2) berpengaruh positif dan signifikan terhadap kinerja karyawan (Y).
\end{abstract}

Kata kunci: Budaya Organisasi, Motivasi Kerja, Kinerja Karyawan 


\section{PENDAHULUAN}

Sumber daya manusia merupakan faktor yang penting dalam suatu organisasi atau perusahaan. Oleh karena itu, sumber daya manusia harus dikelola dengan baik untuk meningkatkan efektivitas dan efisiensi organisasi. Di dalam sebuah perusahaan atau organisasi mempunyai tujuan dan sasaran dalam menghasilkan laba maksimal yang ingin dicapai oleh perusahaan. SDM tidak saja dipandang sebagai unsur produksi, tetapi juga sebagai manusia yang memiliki emosi dan kepribadian aktif yang dapat dijadikan sebagai kekuatan untuk menggerakkan perusahaan. Demikian juga dengan sumber daya manusia pada PT Bandar Abadi yang harus dikelola dengan baik. PT Bandar Abadi Shipyard merupakan perusahaan yang bergerak di bidang manufaktur, perusahaan ini telah beroperasi sejak tahun 2002, dan perusahaan ini bekerja secara berkesinambungan dalam meningkatkan kualitas dan kuantitas produksi pada pembangunan kapal, perbaikan kapal, konversi kapal dan berbagai karya fabrikasi baja. Layanan dan produk PT Bandar Abadi Shipyard telah banyak digunakan di dalam negeri dan internasional. Salah satu hal yang harus menjadi perhatian utama manajer sumber daya manusia pada PT Bandar Abadi ialah budaya organisasi dan motivasi kerja.

Budaya organisasi merupakan nilai-nilai dan norma yang dianut dan dijalankan oleh sebuah organisasi terkait dengan lingkungan dimana organisasi tersebut menjalankan kegiatannya. Budaya yang kuat dapat menghasilkan keunggulan bersaing dan pada akhirnya berhubungan dengan kinerja organisasi. Budaya organisasi penting sekali untuk dipahami karena banyak pengalaman menunjukkan bahwa budaya organisasi tidak saja berbicara mengenai bagaimana sebuah organisasi bisnis menjalankan kegiatannya sehari-hari, tetapi juga sangat mempengaruhi bagaimana kinerja yang dicapai oleh sebuah organisasi bisnis.

Sedangkan motivasi kerja merupakan kekuatan yang muncul dari dalam ataupun dari luar diri seseorang dan membangkitkan semangat serta ketekunan untuk mencapai sesuatu yang diinginkan. Agar sumber daya manusia berkualitas dan memiliki kinerja yang tinggi, maka pihak manajemen perusahaan perlu memikirkan sistem yang dapat meningkatkan kinerja karyawan yaitu pemberian motivasi terhadap karyawan agar dapat membangkitkan semangat dan dorongan untuk melaksanakan tugas secara optimal. Jika dalam pemberian motivasi kepada karyawan kurang efektif dan tidak adil maka hal tersebut akan berdampak langsung terhadap kinerja karyawan.

Dari pengertian di atas dapat diambil kesimpulan bahwa budaya organisasi dan motivasi kerja merupakan faktor penentu keberhasilan dalam kegiatan yang dilakukan perusahaan untuk mencapai tujuan yang ingin dicapai sehingga dari pihak manajemen juga harus memperhatikan bagaimana sistem yang baik untuk meningkatkan sumber daya manusia yang baik bagi perusahaan.

Suatu perusahaan yang berorientasi tinggi dapat dilihat dari hasil kinerja karyawan. Kinerja karyawan yang baik ialah mampu memberikan suatu kontribusi yang terbaik bagi perusahaan atau organisasi ditempat karyawan itu bekerja. Sehingga apa yang dilakukannya dapat mempengaruhi peningkatan pada hasil kerja, baik itu dari segi kualitas maupun kuantitas yang ingin dicapai oleh suatu perusahaan maupun organisasi. Adanya budaya organisasi dan motivasi kerja diharapkan akan meningkatkan kinerja karyawan. Kinerja adalah hasil kerja yang dicapai oleh seorang karyawan dalam melakukan tugas sesuai tanggung jawab yang diberikan kepadanya. Faktor yang mempengaruhi kinerja adalah kemampuan dan faktor motivasi. Setiap organisasi maupun perusahaan akan berusaha untuk meningkatkan kinerja karyawan untuk mencapai tujuan organisasi yang telah ditetapkan.

Berdasarkan latar belakang di atas , berkenaan dengan pentingnya budaya organisasi dan motivasi kerja bagi karyawan, maka penulis tertarik melakukan penelitian dengan judul "Pengaruh Budaya Organisasi dan Motivasi Kerja Terhadap Kinerja Karyawan Pada PT Bandar Abadi Shipyard".

\section{TUJUAN}

Adapun tujuan yang ingin dicapai dalam penelitian ini adalah sebagai berikut:

1. Mengetahui dan menganalisis bagaimana pengaruh budaya organisasi terhadap kinerja karyawan di PT. Bandar Abadi Shipyard 
2. Mengetahui dan menganalisis bagaimana pengaruh budaya organisasi terhadap kinerja karyawan di PT. Bandar Abadi Shipyard

3. Mengetahui dan menganalisis bagaimana pengaruh budaya organisasi dan motivasi kerja secara simultan terhadap kinerja karyawan di PT. Bandar Abadi Shipyard

\section{MANFAAT}

Penelitian ini juga diharapkan akan memberikan manfaat antara lain:

1. Manfaat praktis bagi perusahaan

Manfaat yang didapat untuk perusahaan adalah sebagai masukan dalam pengambilan kebijakan berkaitan dengan budaya organisasi dan motivasi kerja dalam pengaruhnya terhadap kinerja karyawan pada PT Bandar Abadi Shipyard dan kebijakan bagi pimpinan PT Bandar Abadi Shipyard dalam upaya meningkatkan kinerja karyawan.

2. Manfaat Teoritis bagi penulis dan pembaca

a. Bagi penulis, dari penelitian ini diharapkan menambah wawasan dalam manajemen sumber daya manusia, serta memperoleh gambaran nyata yang terjadi sebenarnya dalam lingkungan perusahaan.

b. Bagi pembaca, diharapkan penelitian ini dapat menambah ilmu dan memperluas kajian ilmu Manajemen Sumber Daya Manusia (MSDM) khususnya khususnya budaya organisasi dan motivasi kerja serta pengaruhnya terhadap kinerja karyawan.

\section{KAJIAN PUSTAKA}

\section{Budaya Organisasi}

Pengertian budaya organisasi menurut Rivai dan Mulyadi (2003) budaya organisasi adalah apa yang karyawan rasakan dan bagaimana menciptakan suatu pola teladan kepercayaan, nilai-nilai, dan harapan. Budaya yang dapat menyesuaikan serta mendorong keterlibatan karyawan dapat memperjelas tujuan dan arah strategi organisasi serta yang selalu menguraikan dan mengajarkan nilainilai dan keyakinan organisasi, dapat membantu organisasi mencapai pertumbuhan penjualan, pengembalian modal, keuntungan, mutu dan kepuasaan pelanggan yang lebih tinggi.

Menurut Robbins dan Coulter (2009) mengatakan bahwa budaya organisasi sebagai sebuah sistem keyakinan bersama yang dianut oleh anggota-anggota yang membedakan organisasi tersebut dengan organisasi lain. Ada karakteristik budaya organisasi sebagai berikut :

1. Inisiatif individual adalah tingkat tanggung jawab, kebebasan atau indepedensi yang dipunyai setiap anggota organisasi dalam mengemukakan pendapat.

2. Toleransi terhadap tindakan beresiko adalah suatu budaya organisasi dikatakan baik apabila dapat memberikan toleransi kepada anggota agar dapat bertindak agresif dan inovatif untuk memajukan organisasi serta berani mengambil resiko terhadap apa yang dilakukannya.

3. Pengarahan adalah sejauhmana organisasi atau perusahaan dapat menciptkan dengan jelas sasaran dan harapan yang diinginkan. Sasaran dan harapan tersebut jelas tercantum dalam visi, misi, dan tujuan organisasi.

4. Integrasi adalah sejauhmana organisasi atau perusahaan dapat mendorong unit-unit organisasi untuk bekerja dengan cara yang terkoordinasi.

5. Dukungan manajemen adalah sejauhmana para manajer dapat memberikan komunikasi atau arahan, bantuan, serta dukungan yang jelas terhadap bawahan.

6. Kontrol adalah peraturan-peraturan atau norma-norma yang berlaku di dalam suatu organisasi atau perusahaan.

7. Identitas adalah sejauhmana para anggota suatu organisasi atau perusahaan dapat mengidentifikasikan dirinya sebagai suatu kesatuan dalam perusahaan dan bukan sebagai kelompok kerja tertentu atau keahlian professional tertentu.

8. Sistem imbalan adalah sejauhmana alokasi imbalan (kenaikan gaji, promosi, dan sebagainya) didasarkan atas prestasi kerja pegawai, bukan didasarkan atas senioritas, sikap pilih kasih, dan sebagainya.

9. Toleransi terhadap konflik adalah sejauhmana karyawan di dorong untuk mengemukakan konflik dan kritik secara terbuka.

10. Pola komunikasi adalah sejauhmana komunikasi dibatasi oleh hierarki kewenangan yang formal. 


\section{Motivasi Kerja}

Pengertian motivasi kerja menurut Menurut Siswanto (2009) mengatakan bahwa kekuatan motivasi karyawan untuk bekerja atau berprestasi yaitu seberapa jauh karyawan bekerja keras dan dapat menghasilkan kinerja yang baik atau sebaliknya, karena ada dua faktor jika upaya diubah menjadi kinerja yaitu karyawan harus memiliki kemampuan untuk mengerjakan tugasnya dengan baik dan bagaimana upayanya dapat diubah dengan baik menjadi kinerja.

Menurut Fredick Herzberg ada dua faktor yang mempengaruhi motivasi kerja sesorang dalam organisasi yaitu faktor hygiene dan factor motivator.

\section{Kinerja Karyawan}

Menurut Mangkuprawira dan Hubeis (2007) kinerja adalah hasil dari proses pekerjaan tertentu secara terencana pada waktu dan tempat dari karyawan serta organisasi bersangkutan. Ukuran kinerja dapat dilihat dari sisi jumlah dan mutu tertentu, sesuai standar organisasi atau perusahaan. Hal itu sangat terkait dengan fungsi organisasi dan pelakunya. Menurut buyung (2007), jika kinerja itu adalah hasil kerja yang berupa fisik (hard product) maka dimensinya dapat ditentukan sebagai berikut: kualitas kerja, kuantitas hasil kerjakomunikasi bekerja sendiri, pengetahuan dan keterampilan kerja, tanggung jawab.

\section{METODOLOGI PENELITIAN}

Pada penelitian ini peneliti menggunakan pendekatan penelitian Eksplanatoriy research. Yang menjadi populasi dalam penelitian ini adalah sebanyak 50 responden yaitu karyawan ship building dan ship repairing, dan sampel sebanyak 50 responden dengan menggunakan metode sampling jenuh, semua populasi di jadikan sampel.

Jenis dan sumber data yang digunakan peneliti adalah jenis penelitian kuantitatif dan sumber data yang digunakan adalah data primer dan data sekunder. Data primer dalam penelitian ini berupa data yang dikumpulkan langsung oleh penulis dari responden berupa pertanyaan dari kuisioner dan data sekundernya adalah berupa informasi yang diterima penulis dari berbagai sumber yaitu dari buku, jurnal ilmiah, internet dan dari tempat lokasi penelitian. Dan teknik pengumpulan data yang dilakukan adalah wawancara, kuesioner, dan observasi.

\section{HASIL DAN PEMBAHASAN}

\section{Uji Validitas dan Reliabilitas}

Pengujian validitas instrumen dalam penelitian ini menggunakan software SPSS 20.0 for Windows. Kriteria pengujiannya dilakukan dengan cara membandingkan $r$ hitung dengan $r$ tabel pada taraf $\alpha=0,05$. Jika hasil perhitungan ternyata $r$ hitung $\geq \mathrm{r}$ tabel maka butir instrumen dianggap valid, sebaliknya jika $r$ hitung $\leq r$ tabel maka dianggap tidak valid (invalid), sehingga instrumen tidak dapat digunakan dalam penelitian.

Tabel 1

Hasil Uji Validitas Variabel

\begin{tabular}{|c|c|c|c|}
\hline Item & $\mathbf{r}_{\text {hitung }}$ & $\mathbf{r}_{\text {tabel }}$ & Keterangan \\
\hline X1.1.1 & 0.701 & 0.279 & Valid \\
\hline X1.1.2 & 0.819 & 0.279 & Valid \\
\hline X1.1.3 & 0.767 & 0.279 & Valid \\
\hline X1.2.4 & 0775 & 0.279 & Valid \\
\hline X1.2.5 & 0.617 & 0.279 & Valid \\
\hline X1.2.6 & 0.623 & 0.279 & Valid \\
\hline X1.3.7 & 0.690 & 0.279 & Valid \\
\hline X1.3.8 & 0.573 & 0.279 & Valid \\
\hline X1.3.9 & 0.492 & 0.279 & Valid \\
\hline X2.1.10 & 0.690 & 0.279 & Valid \\
\hline X2.1.11 & 0.836 & 0.279 & Valid \\
\hline X2.1.12 & 0.728 & 0.279 & Valid \\
\hline X2.2.13 & 0.665 & 0.279 & Valid \\
\hline X2.2.14 & 0.683 & 0.279 & Valid \\
\hline X2.2.15 & 0.720 & 0.279 & Valid \\
\hline Y1.1.16 & 0.611 & 0.279 & Valid \\
\hline Y1.1.17 & 0.785 & 0.279 & Valid \\
\hline Y1.118 & 0.876 & 0.279 & Valid \\
\hline Y1.2.19 & 0.555 & 0.279 & Valid \\
\hline Y1.2.20 & 0.728 & 0.279 & Valid \\
\hline Y1.2.21 & 0.854 & 0.279 & Valid \\
\hline Y1.3.22 & 0.797 & 0.279 & Valid \\
\hline Y1.3.23 & 0.656 & 0.279 & Valid \\
\hline S
\end{tabular}

Sumber : Data diolah, 2015

Berdasarkan hasil uji validitas terhadap variabel budaya organisasi, motivasi kerja, dan kinerja karyawan makadapat disimpulkan semua item pertanyaan yang terdiri dari budaya organisasi, motivasi kerja, dan kinerja karyawan dinyatakan VALID. Hal ini 
Lia \& Inggrid, Pengaruh Budaya Organisasi Dan Motivasi Kerja ....

dibuktikan bahwa nilai nilai $\mathrm{r}$ hitung lebih besar daripada $\mathrm{r}$ tabel. $\mathrm{R}$ tabel yang diperoleh sebesar 0.279

\section{Uji Reliabilitas}

Pengertian uji reliabilitas merupakan seberapa besar tingkat kepercayaan yang diperoleh dalam hasil penelitian. Instrumen dapat dikatakan reliabel apabila instrument tersebut cukup dapat dipercaya untuk digunakan sebagai alat pengumpulan data. Peneliti menggunakan rumus Alpha Cronbach. Suatu data dapat dikatakan reliabel apabila reliabilitas mencapai $\geq 0,6$.

Tabel 2

Uji Reliabilitas Variabel

\begin{tabular}{|l|c|c|}
\hline \multicolumn{1}{|c|}{ Variabel } & $\begin{array}{c}\text { Nilai } \\
\text { Reliabilita } \\
\text { s }\end{array}$ & $\begin{array}{c}\text { Keterang } \\
\text { an }\end{array}$ \\
\hline $\begin{array}{l}\text { Budaya Organisasi } \\
\left(\mathbf{X}_{\mathbf{1}}\right)\end{array}$ & 0.850 & reliabel \\
\hline Motivasi Kerja $\left(\mathbf{X}_{\mathbf{2}}\right)$ & 0.794 & reliabel \\
\hline $\begin{array}{l}\text { Kinerja Karyawan } \\
(\mathbf{Y})\end{array}$ & 0.879 & Reliabel \\
\hline
\end{tabular}

Sumber : Data diolah, 2015

\section{Uji Normalitas}

Tabel 3

Hasil Uji Normalitas

\begin{tabular}{|l|c|}
\hline & $\begin{array}{c}\text { Unstandardized } \\
\text { Residual }\end{array}$ \\
\hline $\begin{array}{l}\text { Kolmogorov- } \\
\text { Smirnov }\end{array}$ & 0.682 \\
\hline Asymp-sig. (2 tailed) & 0.741 \\
\hline
\end{tabular}

Sumber : Hasil olahan data SPSS 20

Berdasarkan tabel 3 hasil uji normalitas dapat disimpulkan bahwa nilai Asymp-sig sebesar 0,983 ini berarti data berdistribusi normal. Pada uji normalitas metode Kolmogorov-smirnov data dapat dikatakan normal apabila nilai Asymp- sig lebih dari 0,05 (Asymp sig >0,05).

\section{Uji Multikolonieritas}

Tabel 4

Hasil Uji Multikolonieritas

\begin{tabular}{|l|c|l|l|}
\hline \multirow{2}{*}{$\begin{array}{l}\text { Variabel } \\
\text { Bebas }\end{array}$} & \multicolumn{2}{|c|}{$\begin{array}{c}\text { Collinearity } \\
\text { Statistics }\end{array}$} & \multirow{2}{*}{ Keterangan } \\
\cline { 2 - 3 } & $\begin{array}{c}\text { Toleran } \\
\text { ce }\end{array}$ & VIF & \\
\hline $\begin{array}{l}\text { Budaya } \\
\text { Organisasi } \\
\text { (X1) }\end{array}$ & 0.862 & 1.160 & $\begin{array}{l}\text { Bebas } \\
\text { Multikolinie } \\
\text { ritas }\end{array}$ \\
\hline $\begin{array}{l}\text { Motivasi } \\
\text { Kerja (X2) }\end{array}$ & 0.862 & 1.160 & $\begin{array}{l}\text { Bebas } \\
\text { Multikolinie } \\
\text { ritas }\end{array}$ \\
\hline
\end{tabular}

Sumber : Data diolah, 2015

Berdasarkan tabel 4 hasil uji multikolonieritas dapat disimpulkan bahwa budaya organisasi dan motivasi kerja tidak terjadi gejala multikolonieritas karena nila VIF (Variaance Influence Factor) yang dihasilkan $<10$.

\section{Uji Heteroskedastisitas}

Pada penelitian ini penulis menggunakan 2 metode dalam menentukan uji heteroskedastisitas yaitu menggunakan metode grafik Scatter Plot dan menggunakan metode Glejser.

Tabel 6. Hasil uji heteroskedastisitas

Tabel 5

Hasil uji heteroskedastisitas

\begin{tabular}{|c|c|c|}
\hline Variabel & Sig & Keterangan \\
\hline $\begin{array}{c}\text { Budaya } \\
\text { Organisasi }\end{array}$ & 0.906 & $\begin{array}{c}\text { Tidak terjadi masalah } \\
\text { heterokedastisitas }\end{array}$ \\
\hline $\begin{array}{c}\text { Motivasi } \\
\text { Kerja }\end{array}$ & 0.094 & $\begin{array}{c}\text { Tidak terjadi masalah } \\
\text { heterokedastisitas }\end{array}$ \\
\hline
\end{tabular}

Sumber : Data doilah, 2015

Berdasarkan tabel 5 di atas hasil uji heterokedastisitas dapat dijelaskan bahwa penelitian ini terbebas dari asumsi heterokedastisitas, terlihat bahwa nilai sig lebih dari 0,05 . Kriteria pengujian yang dilakukan apabila nilai sig $>0,05$ maka tidak terjadi heteroskedastisitas. Uji heterokedastisitas ini menggunakan uji gletser dengan bantuan SPSS 20. 


\section{Uji Regresi Linear Berganda}

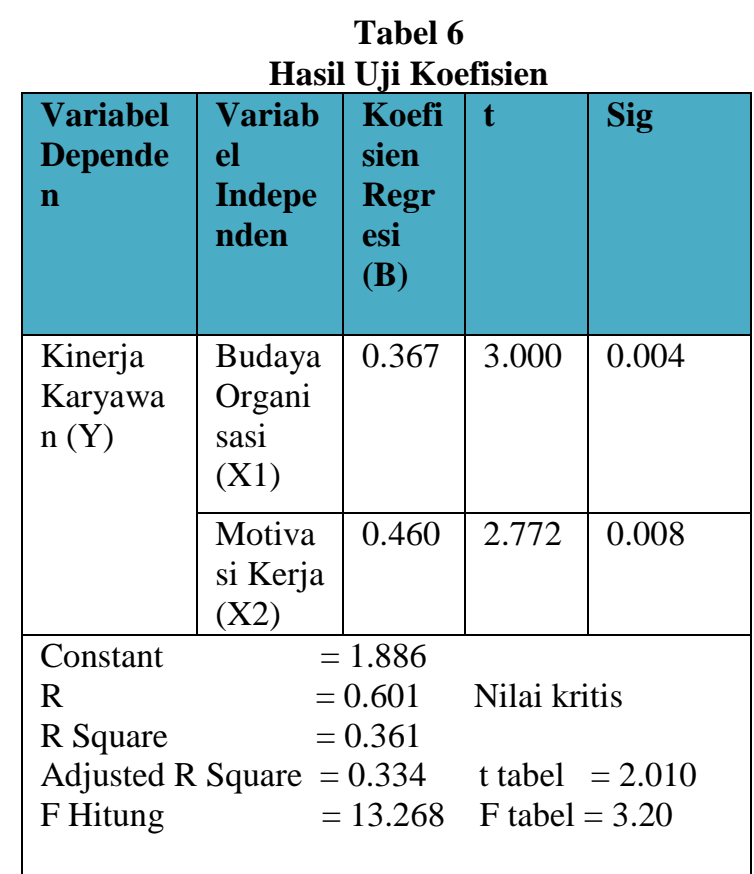

Sumber : Data dioleh penulis, 2015

\section{Pengujian Hipotesis 1}

Hipotesis 1 menyatakan adanya pengaruh positif dan signifikan antara variabel budaya organisasi terhadap kinerja karyawan. Berdasarkan tabel 4.13 dapat dijelaskan bahwa variabel independen (X1) budaya organisasi terhadap variabel kinerja karyawan (Y) adalah sebesar $\mathrm{t}_{\text {hitung }} 3.000>\mathrm{t}_{\text {tabel }} 2.010$ dengan tingkat signifikan $(0.004)<0.05$ maka hipotesis 1 yang diajukan dalam penelitian ini diterima. Dapat disimpulkan bahwa terdapat hubungan yang positif dan signifikan antara antara budaya organisasi dengan kinerja karyawan.

\section{Pengujian Hipotesis 2}

Hipotesis 2 menyatakan adanya pengaruh positif dan signifikan antara variabel motivasi kerja terhadap kinerja karyawan. Variabel independen motivasi kerja (X2) dengan kinerja karyawan (Y) adalah $\mathrm{t}_{\text {hitung }}$ sebesar $2.772>$ $\mathrm{t}_{\text {tabel }} 2.010$ dan tingkat signifikan $(0.008)<$ 0.05 maka hipotesis 2 yang diajukan dalam penelitian ini diterima. Dapat disimpulkan bahwa terdapat hubungan yang positif dan signifikan antara antara motivasi kerja dengan kinerja karyawan.

\section{Pengujian Hipotesis 3}

Hipotesis 3 menyatakan terdapat pengaruh positif dan signifikan secara simultan antara variabel budaya organisasi dan motivasi kerja terhadap kinerja karyawan. Hasil uji hipotesis ditunjukkan pada uji $\mathrm{F}$ sebesar $13.268>\mathrm{F}_{\text {tabel }}$ 3.20 dengan nilai signifikansi t lebih kecil 0.05 yaitu sig f 0.000 sehingga dapat disimpulkan bahwa hipotesis 3 yang diajukan dalam penelitian ini diterima, budaya organisasi dan motivasi kerja dapat meningkatkan kinerja karyawan.

\section{KESIMPULAN}

Berdasarkan hasil analisis yang dilakukan maka dapat ditarik kesimpulan sebagai berikut

1. Terdapat pengaruh positif dan signifikan budaya organisasi terhadap kinerja karyawan pada PT. Bandar Abadi Shipyard secara parsial. Hasil ini dapat dilihat dari $\mathrm{t}$ hitung variabel budaya organisasi $\mathrm{t}_{\text {hitung }} 3,000>\mathrm{t}_{\text {tabel }} 2,010$ dengan tingkat signifikan $(0,004)<0,05$.

2. Terdapat pengaruh positif dan signifikan motivasi kerja terhadap kinerja karyawan pada PT. Bandar Abadi Shipyard secara parsial. Hasil ini dapat dilihat dari thitung variabel motivasi kerja sebesar 2,772 > $\mathrm{t}_{\text {tabel }} 2,010$ dan tingkat signifikan $(0,008)<$ 0,05 .

3. Terdapat pengaruh positif dan signifikan Budaya organisasi dan motivasi kerja pada PT. Bandar Abadi Shipyard secara simultan. Hasil ini dapat dilihat dari $\mathrm{F}$ hitung sebesar 13,268 dengan tingkat signifikan sebesar $0,000<0,05$. Pengaruh variabel budaya organisasi dan motivasi kerja terhadap kinerja karyawan sebesar $36,1 \%$ sedangkan sisanya $63,9 \%$ dipengaruhi oleh variabel lain diluar penelitian ini.

\section{SARAN}

Berdasarkan hasil penelitian dan simpulan yang diperoleh, maka saran yang dapat disampaikan adalah :

1. Budaya organisasi terhadap kinerja karyawan pada PT Bandar Abadi Shipyard sangat baik, sehingga pimpinan perusahaan perlu mempertahankan dengan membangun iklim kerja yang mendukung budaya organisasi untuk mempengaruhi karyawan dalam meningkatkan kinerjanya.

2. Karyawan harus dapat mempertahankan motivasi kerja yang sudah dirasakan oleh 
Lia \& Inggrid, Pengaruh Budaya Organisasi Dan Motivasi Kerja ....

para karyawan sehingga karyawan memiliki kinerja yang baik.

3. Karena semua variabel yang diteliti dalam penelitian ini menunjukkan pengaruh positif dan signifikan maka diharapkan bagi pimpinan perusahaan PT Bandar Abadi Shipyard untuk membuat kebijakan perusahaan yang bisa mempertahankan indikator-indikator dari budaya organisasi dan motivasi kerja yang ada sekarang.

4. Diharapkan bagi peneliti berikutnya agar menambah variabel selain budaya organisasi dan motivasi kerja agar lebih memahami variabel-variabel lain yang mempengaruhi kinerja karyawan.

\section{DAFTAR PUSTAKA}

Arikunto, S. (2006). Prosedur Penelitian Suatu Pendekatan Praktik, Jakarta : Rineka Cipta

Coulter Mary, \& Robbins Stephen. (2009). Manajemen. Jilid 1. Edisi Delapan. Edisi Bahasa Indonesia. Jakarta : PT Indeks.

Darmawan. (2013). Prinsip-Prinsip Perilaku Organisasi. Surabaya: PT. Jepe Press Media Utama.

Deikme, Pilatus. (2013). Motivasi Kerja Dan Budaya Organisasi Pengaruhnya Terhadap Kinerja Pegawai Bagian Keuangan Sekda Kabupaten Mimika Provinsi Papua. Jurnal EMBA, 1 (3), 980-986.

Ghozali, I. (2006). Aplikasi Analisis Multivariate dengan Program SPSS. Semarang:

Badan Penerbit Universitas Diponegoro.

Rimpulaeng, K., \& Sepang, J. L. (2014). Motivasi Kerja, Komitmen Karyawan, Dan Budaya Organisasi, Pengaruhnya Terhadap Kinerja Karyawan PT. Gudang Garam Manado. Jurnal EMBA, 2 (3), 137-148.

Rivai Veithzal dan mulyadi deddy. (2003). Kepemimpinan dan perilaku organisasi. Jakarta: PT Rajagrafindo Persada

Sirait, Justin T dan Rahardjo Purwanto. (2009). Mengelola dan Mengembangkan Sumber Daya Manusia. Jakarta : Mitra Wacana Media

Siswanto. (2009). Pengantar Manajemen. Jakarta: PT Bumi Aksara
Sunyoto, Danang. (2012) . Manajemen Sumber daya Manusia. Yogyakarta: CAPS (Center for academic Publishing service)

Sugiyono. (2009). Metode Penelitian Bisnis dan R \& D. Bandung: Alfabeta

Sugiyono. (2014). Metode Penelitian Manajemen. Bandung: Alfabeta

Sule Tisnawati Ernie \& saefullah Kurniawan. (2005). Pengantar Manajemen. Jakarta : kencana budaya organisasi

Trang, Dewi Sandy. (2013). Gaya Kepemimpinan Dan Budaya Organisasi Pengaruhnya Terhadap Kinerja Karyawan. Jurnal EMBA, 1 (3).

Umam, Khaerul. (2010). Perilaku Organisasi. Bandung:Pustaka setia robbins

Wibowo. (2007). Manajemen Kinerja. PT Rajagrafindo Persada, Jakarta.

Widyaningrum, Muhammad Enny. (2011). Influence Of Motivation And Culture On Organizational Commitmen And Performance Of Employee Of Medical Services. SAVAP Internasional, 1 (3).

Yamsul, P., Surachman, Salim, U., \& Armanu. (2013). The Influence of Motivation And Organization Culture On Work Satisfaction And Organizational Commitment (Study On National Society Empowerment Program In Southeast Sulawesi Province. International Journal of Business and Management Invention, 2 (9). 